\title{
The Value of Linking Mitigation and Adaptation: A Case Study of Bangladesh
}

\author{
Jessica M. Ayers $\cdot$ Saleemul Huq
}

Received: 13 July 2007/ Accepted: 23 September 2008

(C) Springer Science+Business Media, LLC 2008

\begin{abstract}
There are two principal strategies for managing climate change risks: mitigation and adaptation. Until recently, mitigation and adaptation have been considered separately in both climate change science and policy. Mitigation has been treated as an issue for developed countries, which hold the greatest responsibility for climate change, while adaptation is seen as a priority for the South, where mitigative capacity is low and vulnerability is high. This conceptual divide has hindered progress against the achievement of the fundamental sustainable development challenges of climate change. Recent attention to exploring the synergies between mitigation and adaptation suggests that an integrated approach could go some way to bridging the gap between the development and adaptation priorities of the South and the need to achieve global engagement in mitigation. These issues are explored through a case study analysis of climate change policy and practice in Bangladesh. Using the example of waste-to-compost projects, a mitigation-adaptation-development nexus is demonstrated, as projects contribute to mitigation through reducing methane emissions; adaptation through soil improvement in drought-prone areas; and sustainable development, because poverty is exacerbated when climate change reduces the flows of ecosystem services. Further, linking adaptation to mitigation makes mitigation action more relevant to policymakers in Bangladesh, increasing engagement in the
\end{abstract}

J. M. Ayers ( $\square)$

Development Studies Institute, London School of Economics, Houghton Street, London WC2A 2AE, UK

e-mail: j.m.ayers@1se.ac.uk

S. Huq

International Institute of Environment and Development,

3 Endsleigh Street, London WC1H ODD, UK

e-mail: saleemul.huq@iied.org international climate change agenda in preparation for a post-Kyoto global strategy. This case study strengthens the argument that while combining mitigation and adaptation is not a magic bullet for climate policy, synergies, particularly at the project level, can contribute to the sustainable development goals of climate change and are worth exploring.

Keywords Adaptation - Mitigation ·

Climate change responses - Sustainable development .

Bangladesh · South Asia

There are two principal strategies for managing climate change risks: mitigation, the limiting of greenhouse gasses (GhGs), particularly carbon dioxide and methane, to mitigate further climate change; and adaptation, which accepts that some degree of climate change is already inevitable and seeks to limit the negative impacts. Both mitigation and adaptation are clearly necessary in any comprehensive approach to managing climate change (Klein and others 2007; Dowlatabadi 2007; Willbanks and others 2003). Even the most stringent mitigation efforts cannot avoid further impacts of climate change, because of historically committed emissions, making action on adaptation essential. At the same time, we cannot adapt indefinitely to these impacts, so urgent mitigation is needed to avoid the worst effects of climate change (Willbanks and others 2007a; King 2004).

Mitigation and adaptation share the same ultimate purpose: to reduce the undesirable impacts of climate change (Swart and Raes 2007). They are inherently linked in the climate system, because the more effective mitigation undertaken now, the less need for adaptation in the future. However, despite the consensus on the need for both adaptation and mitigation, and recognition of the 
relationship between them, until recently they have been considered separately both in the international policy arena and in the literature (Swart and Raes 2007; Ravindranath 2007; Jones and others 2007). Mitigation has been treated as an issue for developed countries, which hold the greatest responsibility for climate change, while adaptation is seen as a priority for the South, where mitigative capacity is lower and vulnerability is high. The mitigation research community has focused strongly on technological and economic issues, and has traditionally relied on 'top-down' aggregate modeling to inform mitigation strategies that take a global systemic approach to limiting cumulative greenhouse gasses over the long term; on the other hand, the adaptation research community emphasizes local and place-based analysis, sharing a research approach with the development studies and disaster risk-reduction communities that minimizes immediate- and short-term impacts of climate trends and shocks in the most vulnerable, primarily developing, countries (Klein and others 2007).

This paper suggests that the separate treatment of mitigation and adaptation in both science and policy has hindered progress against the fundamental sustainable development challenges of climate change. The countries most vulnerable to climate change are usually taken to be the least developed countries (LDCs), small island developing states, and those countries whose economies are heavily reliant on climate-sensitive activities, principally Africa (Huq and Ayers 2007; Huq and Burton 2003). Adaptation priorities in the South are therefore increasingly recognized as synonymous with sustainable development objectives. Yet, viewed as separate and, in some cases, counterproductive to action on mitigation until recently, adaptation has historically been treated as a marginal policy option by climate change scientists and decision makers, mitigation's "poor cousin" in the climate policy arena (Pielke and others 2007). Although perspectives have recently changed and adaptation is now a prominent aspect of the climate change policy agenda, relative to mitigation adaptation continues to be insufficiently supported by appropriate fiscal and institutional mechanisms.

At the same time, mitigating GHG emissions is a marginal policy concern for vulnerable developing countries (Venema and Rehman 2007). The Clean Development Mechanism $(\mathrm{CDM})$ is a market-based initiative under the Kyoto Protocol allowing countries with GHG reduction targets to generate emissions 'credits' from projects that offset emissions in developing countries and produce sustainable development benefits (Taiyab 2006). The CDM has gone some way in providing incentives for the participation of developing countries in mitigation and aligning sustainable development objectives of the South with the mitigation agenda. However, the development benefits of the CDM have been criticized for being more hypothetical than real (Brown and others 2004), and the most vulnerable LDCs have little to gain from policies which reward reductions in GhGs because they are, almost by definition, the smallest contributors to the global GhG burden. This is concerning given the necessity for eventual engagement of all developing countries in a comprehensive post-Kyoto global mitigation strategy.

Recently, increased attention to the linkages between mitigation and adaptation has led to new work in this area (see Swart and Raes 2007; Klein and others 2007; Willbanks and others 2007a) which suggests that an integrated approach could offer benefits over two independent, parallel strategies in relation to overcoming the policy divide between the South's adaptation needs and the North's mitigation priorities (Venema and Rehman 2007). This paper seeks to contribute to this emerging literature by considering whether in vulnerable developing countries, where mitigative capacity is low and adaptation needs are high, linking adaptation to mitigation at the project level provides an avenue for integrating core sustainable development priorities with climate policy while simultaneously encouraging the engagement of local policymakers in the mitigation agenda. This will be explored through a detailed illustrative case study analysis of Bangladesh, an LDC which has been frequently cited as one of the most vulnerable countries to climate change (Rahman 1997; Ahmed and others 1999; Venema and Cisse 2004) and where the potential for gains to be made from mitigation has been cited as low (Ahmed and others 1999).

This paper begins with a discussion of the contradictions and interactions between mitigation and adaptation, and describes how their separate treatment in both science and policy has hindered progress on adaptation and sustainable development, exacerbating sensitive issues of North-South equity within the international climate policy arena. Existing work on the synergies between mitigation and adaptation is reviewed and it is shown that in some cases linking mitigation and adaptation can contribute to the achievement of sustainable development objectives in climate policy and practice. These issues are illustrated through a case study analysis of Bangladesh, and it is suggested that, by supporting links between mitigation and adaptation at the project level in Bangladesh, adaptation and sustainable development needs can be addressed while encouraging engagement of policymakers in the global mitigation agenda.

\section{Adaptation and Mitigation: A Divisive Approach to Managing Climate Change}

Adaptation and Mitigation in International Negotiations

Historically, adaptation and mitigation have been perceived and treated as separate climate change management 
strategies in both science and policy, with mitigation dominating policy discourse and action until relatively recently. When climate change was formally taken up by the U.N. General Assembly for the first time in 1988, it was considered to be in a similar vein to the issues of acid rain and the ozone layer, both cross-border, systemic environmental issues which required international cooperation to manage (see Litfin 1994 and Hajer 1995 for detailed discussions of the governance issues surrounding the management of these two issues). Climate change uncritically followed the pattern of governance of both, with a targets and timetable approach that sought to mitigate impacts (Munasinghe and Swart 2004), adopting a policy framework based on 'neutral' scientific assessments by epistemic communities (hence the establishment of the Intergovernmental Panel on Climate Change; IPCC); to communicate these results to policymakers (the U.N. Framework Convention on Climate Change; UNFCCC); and then to initiate a state-led environmental regime based on international targets that were regularly updated and strengthened (such as Kyoto). The powerful notions that science is neutral, expert networks are benign and representative, and governments act rationally according to expert advice served to strengthen the legitimacy of the mitigation approach. In this way mitigation came to dominate our understanding of climate change management, and institutional structures emerged to support it. Little attention was given to the impacts of climate change, less still those in the most vulnerable developing countries.

The IPCC clearly distinguishes adaptation and mitigation as separate approaches in climate change management. Adaptation has been defined by the IPCC (2001) as "adjustment in natural or human systems in response to actual or expected climatic stimuli or their effects, which moderates harm or exploits beneficial opportunities." This is distinct from the mitigation approach, defined by the IPCC (2001) as any "anthropogenic intervention to reduce the sources or enhance the sinks of greenhouse gasses." In the latter, climate change is presented as a universal systemic issue, with the focus on cumulative global reduction of GhGs, leading to a cumulative global reduction in climate change risk. Out of this approach have sprung emissions trading schemes, carbon emissions capping, and the hope of achieving GhG reduction targets 'in time' to prevent worse-case scenarios of global warming. Adaptation, on the other hand, has more localized and immediate implications for vulnerability reduction. This separation is reinforced in the IPCC reports, where Working Group II addresses adaptation and Working Group III addresses mitigation (Ravindranath 2007).

In the last decade, attention to adaptation has increased with the recognition that because of historical emissions, the near-term impacts of climate change are unavoidable and are beginning to be observable, and that developing countries are particularly vulnerable. Adaptation has therefore emerged as a priority for the South, an issue closely related to development and disaster risk reduction, and in contrast to the hard, quantifiable outcomes of mitigation activity (reduction in GhGs), adaptation is complex and messy, context specific, and difficult to quantify. Interpretations and goals of adaptation are less clear-cut, and include policy-based institutional arrangements, for example, agricultural and land tenure policies; public/private investment in technologies such as building infrastructure, irrigation systems, and large-scale embankments; and more recent livelihoods-based approaches, which overlap (and indeed, many argue, are interchangeable) with development activities such as communitybased low-tech irrigation systems, through to decreasing social vulnerability, for example, with livelihoods diversification programs. As noted by the IPCC (2007), "The array of potential adaptive responses available to human societies is very large, ranging from purely technological (e.g., sea defenses), through behavioral (e.g., altered food and recreational choices), to managerial (e.g., altered farm practices) and to policy (e.g., planning regulations)."

Mitigation and adaptation have therefore been distinguished in terms of spatial, temporal, and socioeconomic scales (Jones and others 2007; Willbanks and others 2007b). Spatially, the benefits of mitigation are perceived to be greater at the global scale and external to a local area, while adaptation necessitates locally appropriate actions that have context-specific benefits for the countries and regions that implement them; temporally, adaptation reduces vulnerability to immediate and near-term climate risks while the effects of mitigation are only apparent over longer time scales; finally, adaptation is more of a priority for vulnerable developing countries, whose mitigative capacity is lower than in the North yet whose vulnerability to climate change is acute, while mitigation is prioritized by industrialized countries that hold the greatest responsibility for climate change.

\section{The Consequences of a Divided Approach for} Sustainable Development Objectives

The distinction between mitigation and adaptation has resulted in policymakers and negotiators treating the two as policy alternatives or even in opposition, resulting in inadequate attention being paid to adaptation (Dang and others 2003). As noted in the preceding section (Adaptation and Mitigation in International Negotiations), the adaptation agenda emerged separately and in the shadow of mitigation, and until recently it received relatively little attention and support in the global climate change policy frameworks. This is significant in terms of addressing 
sustainable development because adaptation is more closely aligned with the development objectives of the South than mitigation. In practice, because adaptation requires reducing vulnerability and increasing adaptive capacity, there is a significant amount of overlap with development methodologies (Huq and Reid 2007).

Yet the divide between adaptation and mitigation has stalled effective action on adaptation. Embedded within the mitigation discourse has been a wariness of prioritizing adaptation, and this penetrates mitigation advocacy rhetoric, because as articulated by Kjellen (2006), adaptation raises (at this stage theoretical) concerns that "some countries might consider their national costs of adaptation to be so much lower than the costs of mitigation that "no mitigation action' could be seen as a tempting prospect." Such a line of argument has been taken in the past by $\mathrm{Al}$ Gore, currently perhaps one of the most visible political advocates of taking action on climate change, who has argued that "believing that we can adapt to just about anything is ultimately a kind of laziness, an arrogant faith in our ability to react in time to save our skin" (Gore 1992, cited by Pielke 2007). This would be an extreme position, but it illustrates the dilemma of reconciling national interest with the global interest, and the close relationship between mitigation and adaptation (Kjellen 2006).

Perspectives have recently changed and adaptation is now recognized as an essential part of climate policy alongside mitigation. This recognition was translated into policy at the Seventh Conference of the Parties to the UNFCCC (COP 7) in Marrakech in 2001 with the creation of three new funds for adaptation, including the Adaptation Fund, financed by a $2 \%$ levy on the CDM. In Bali in 2007, COP 13 finally brought adaptation onto equal footing with mitigation by highlighting it as one of the four 'building blocks' to come out of the negotiations, alongside mitigation, technology cooperation, and finance. Yet, despite this progress, there remains some degree of institutional bias toward mitigation over adaptation, limiting the scope of action on adaptation to contribute to sustainable development. The dominance of a mitigation-focused agenda has resulted in an understanding of climate change that is scientific, technical, and environmental, which has penetrated climate policy frameworks. Correspondingly, the UNFCCC treats adaptation in the narrowest sense, as an issue of climate change, with adaptation actions limited to changes that are proven to be anthropogenic (Pielke and others 2007). However, given that environmental vulnerability is derived largely from a political, economic, and social context, and not simply physical exposure to some environmental catastrophe (Cannon 2000), effective adaptation to climate change should include core development concerns associated with vulnerability including but not limited to those directly caused by climate change. The focus on mitigation has created climate change policy frameworks that do not fit with defining adaptation in terms of sustainable development (Pielike and others 2007).

Further, relative to mitigation investment in adaptation remains woefully inadequate. The cost of adaptation is huge. Estimates generated by the World Bank put the figure at between $\$ 10$ billion and $\$ 40$ billion annually for climate-proofing investments in developing countries. This figure has since been criticized for being too conservative, and more recent estimates by Oxfam International (2007) put the figure at more than $\$ 50$ billion annually. Yet the World Bank (2006) estimates (very optimistically) that the Adaptation Fund may amount to $\$ 100$ million to $\$ 500$ million per year, while contributions to the Marrakech funds managed by the Global Environment Facility may amount to \$200 million per year.

Finally, separating adaptation from mitigation has further detached action on mitigation from sustainable development, reinforcing the notion that mitigation is a problem for the North, while adaptation is a Southern priority, alienating vulnerable developing countries from engagement in mitigation action. As highlighted at the Eighth Conference of the Parties (COP 8) in Delhi in 2002, and acknowledged in the resulting Delhi Declaration, while global reductions in GhGs are necessary to avoid the worst impacts of climate change, this is a marginal policy concern when "economic and social development and poverty eradication are the first and overriding priorities of developing country partners" (UNFCCC 2002). Although the CDM, which encourages climate-friendly investment in developing countries, is intended to contribute to social and developmental benefits in host countries, achieving this "development dividend" in mitigation projects has proved problematic, not least because diversifying projects away from cheaper forms of climate mitigation to achieve development outcomes decreases the efficiency and increases costs of mitigation (Forsyth 2007; Klein and others 2007). For the poorest and most vulnerable developing countries, therefore, mitigation is not very urgent or even very relevant (Swart and Raes 2007). From this perspective, attempts to carry out mitigation action in developing countries have highlighted key equity issues that underscore international climate policy, and have resulted in criticisms of the North by the South of environmental imperialism (Dowlatabadi 2007; Forsyth 2003). However, it is essential that developing countries are engaged in mitigation, given that the South's emissions are increasing rapidly; further, as pointed out by Golkany (2007), given that a substantial portion of economic growth in developing countries is attributable to trade and remittances from developed countries, there is an argument that developing countries do bear some responsibility for historic emissions contributions, albeit not equal to that of the industrialised nations. 
The divide between mitigation and adaptation has therefore resulted in the historical dominance of the mitigation agenda over adaptation priorities, stifling progress on adaptation and engagement of the South in the global climate change effort. Given the growing recognition of the role that developing countries play in the success of global climate change policies (Müller 2002), incentives are needed for mitigation options to be politically and financially practical in the South (Halsnaes and Verhagen 2007; Willbanks and Sathaye 2007). At the same time, there is a need to strengthen fiscal and institutional support for adaptation and sustainable development. Recently, attention has been paid to exploring the synergies between mitigation and adaptation to achieve cobenefits and 'winwin' options for climate policy globally and in developing countries (Klein and others 2007; Willbanks and others 2007a). It has been suggested that linking adaptation to mitigation in some cases may contribute to repairing the discursive rift between climate policy and sustainable development (Venema and Rehman 2007). This paper reviews recent work in this emerging field, before exploring the potential for linking mitigation and adaptation at the project level to contribute to sustainable development objectives in climate policy through a case study of one of the most vulnerable LDCs, Bangladesh.

\section{Linking Mitigation and Adaptation}

\section{Existing Work on Linking Mitigation and Adaptation}

One way of overcoming the conceptual divide between mitigation and adaptation is to consider the synergies between them. The benefits of this are twofold. First, in the short term, we can channel some fiscal and institutional support currently provided for mitigation toward adaptation, where it is much needed, and achieve both, creating a 'win-win' solution. Second, in the longer term, by linking mitigation and adaptation, we can help overcome the persistent conceptual divide between the two, and empower the adaptation agenda within the international climate change frameworks. In addition, this will increase the relevance of mitigation for the most vulnerable developing countries, moving beyond the perception of mitigation as an issue only for the North.

Recent work in science and policy has begun to explore the synergies between mitigation and adaptation and consider the opportunities for adopting an integrated approach to managing climate change (Willbanks and others 2003, 2007a, b; Dang and others 2003; Klein and others 2007; Venema and Cisse 2004; Venema and Rehman 2007). Conceptually, there is a very clear link between mitigation and adaptation under the climate regime, understood as the "cause and effect" interaction (Dang and others 2003), which means that future adaptation requirements are related to the current levels of mitigation; as noted by Willbanks and others (2007b), "If mitigation can be successful in keeping impacts at a lower level, adaptation can be successful in coping with more of the resulting impacts" (714). Further, many of the theoretical distinctions between mitigation and adaptation described under Adaptation and Mitigation: A Divisive Approach to Managing Climate Change (above) do not stand when considered more carefully. For example, in terms of spatial and temporal scale, it is commonly asserted that adaptation is local and immediate in action and benefit, while mitigation is local in costs but global in benefits, and benefits of mitigation are only manifest over the longer term (Jones and others 2007). Yet, as pointed out by Golkany (2007), adaptation may also have global benefits where it reduces threats to biodiversity and natural systems, while benefits can be long term because addressing risks under current climate-sensitive circumstances can reduce future vulnerability to climate change as well as reducing immediate risks. In addition, Jones and others (2007) note that while the demand of mitigation is for the global good, it can also be local, because demand for mitigation will be highest when and where adaptive capacity is exceeded, and the supply of mitigative capacity is certainly local.

Adaptation and mitigation are also linked in tangible ways at the international, national, and local level. The Fourth Assessment Report of the IPCC for the first time introduced a chapter dedicated to the interrelationships between adaptation and mitigation, recognizing the dual need for both and encouraging policymakers to express an interest in exploring the synergies and tradeoffs between them (Klein and others 2007). International action on climate change links adaptation and mitigation through the Adaptation Fund, which is financed by a $2 \%$ levy on the CDM; hence the more effective the CDM is, the greater the level of funding for adaptation (Burton 2000; Pielke and others 2007). At the national and sectoral level, adaptation and mitigation actions and policies tend to involve different sectors, so decisions on adaptation are not well integrated into comprehensive 'climate change' strategies. Mitigation actions tend to focus on the energy, transport, and industry sectors, while the sectors most vulnerable to climate change and of concern to adaptation decision makers are usually agriculture, land use, forestry, and coastal zone management (Huq and Grubb 2007). However, there is certainly potential for overlap at the sectoral level; for example, adaptation policies in the agriculture, land use, and forestry sectors carry implications for $\mathrm{CO}_{2}$ sequestration and avoid methane emissions (Dang and others 2003; Rozenweig and Tubiello 2007).

Opportunities for 'win-win' mitigation and adaptation integrated approaches are most likely at the local level, 
where they are linked in more action-specific ways (Huq and Grubb 2007; Willbanks and others 2007b). Many adaptive actions have consequences for mitigation, and mitigation actions can have consequences for adaptation (Klein and others 2007). These consequences may be positive or negative. Relationships at the project level can be very direct, involving the same resource base or stakeholders, for example, through the building of coastal mangrove plantations to build resilience to coastal storms that can also sequester carbon (Huq and Grubb 2007). Mitigation actions can also affect adaptive capacity, for example, through more efficient energy use that promotes local development or CDM projects on land use or land energy that support local economies and livelihoods (Klein and others 2007). Progress with either mitigation or adaptation can therefore, in some cases, reduce payoffs for the other (Willbanks and others 2007b).

\section{Linking Mitigation and Adaptation in the Context of} Sustainable Development

Exploring the synergies between mitigation and adaptation, particularly at the project level, can contribute to addressing the sustainable development challenges of climate change policy in developing countries, by reducing costs and increasing cobenefits. Because adaptation actions are largely synonymous with development, strategies that link mitigation to adaptation in developing countries can increase adaptive capacity and reduce vulnerability while encouraging socioeconomic development paths that also mitigate emissions, all of which are tied to sustainable development. Venema and Rehman (2007) argue that the mitigation-adaptation synergy is intrinsic to the ecosystemoriented sustainable development objectives counseled at the World Summit on Sustainable Development in its Plan of Implementation, because poverty is both a driver and an outcome of critical sustainable development-climate linkages such as energy deprivation and deforestation. Projectlevel integration of mitigation and adaptation in the context of sustainable development has significant potential in this regard. For example, Venema and Cisse (2004) have shown that ecosystem-oriented decentralized rural energy projects in developing countries can address core sustainable development priorities and build adaptive capacity without increasing GhG emissions. (Venema and Cisse 2004; see also Venema and Rehman 2007). Further, by linking mitigation and adaptation in the context of sustainable development, incentives are provided for vulnerable countries with low mitigative capacity to become engaged in mitigation, addressing the South's adaptation needs and the North's mitigation priorities (Venema and Rehman 2007). Linking analyses of mitigation and adaptation in a context of sustainable development is therefore likely to identify a larger pool of potential 'win-win' options and policies (Huq and Grubb 2007).

While the potential for project-level integration of mitigation and adaptation in contributing to sustainable development objectives is clear, there is a need for greater field demonstration to link academic arguments to realities on the ground. The next section of this paper explores synergies between mitigation and adaptation in Bangladesh, an LDC where mitigation opportunities are low, while adaptation needs are high. A historical analysis of the evolution of climate change policy in Bangladesh will illustrate the way in which a divisive approach to managing climate change has had detrimental consequences for encouraging action on mitigation in Bangladesh and for facilitating appropriate action on adaptation. Synergies between mitigation and adaptation are explored and it is shown that encouraging linkages between mitigation and adaptation at the project level can contribute to sustainable development while improving both adaptive and mitigative capacity.

\section{Linking Mitigation and Adaptation in Bangladesh}

This section explores how the institutional bias toward mitigation in the global climate negotiations has affected the evolution of Bangladesh's national climate change policy, and whether opportunities exist to link adaptation and mitigation in Bangladesh within this institutional setting. The lack of published literature available means that the following analysis is largely adapted from key informant interviews and unpublished data. As far as possible, all material has been cross-referenced with other sources, but any factual inaccuracies remain the authors' responsibility.

Bangladesh was chosen as an appropriate case study because, first, it is frequently cited as one of the most vulnerable LDCs to climate change (Rahman 1997; Ahmed and others 1999; Venema and Cisse 2004); second, it is one of the LDCs least responsible for the causes of climate change-hence the desirability of, as well as potential for, mitigating opportunities is low. Ahmed and others (1999) note, for example, that a study exploring mitigation options in Bangladesh reported that projects would not be significant with respect to global emissions reductions. Third, the potential for linkages among mitigation, adaptation, and sustainable development exists; for example, with regard to adaptation and mitigation linkages via decentralized renewable technology, Venema and Cisse (2004:172) note, "In Bangladesh ... the mitigation-nexus is particularly striking." Fourth, Bangladesh is particularly interesting because of its relatively long history of both environmental and climate change awareness, policy, and action, 
compared to the other LDCs. It is party to many International Multilateral Environmental Agreements and is signatory to the UNFCCC (Alam 2003).

\section{Climate Change Policy in Bangladesh}

A list of key milestones of Bangladesh's national efforts to address climate change is given in Box 1. An review of these milestones reveals the following observations. First, awareness of climate change occurs surprisingly early on compared with that in most other developing or even developed countries, however, there is a striking lag between awareness and policy. Second, the focus on adaptation relative to mitigation is perhaps less than we might expect given the need for adaptation versus the limited scope for mitigation. Third, despite the academic attention to mitigation in Bangladesh as evidenced by the multiple studies carried out, there have only been four projects approved for CDM (only two of which are actually up and running).

Awareness of climate change began in the academic community in Bangladesh as early as the mid 1980s, and Dr. Atiq Rahman, now Director of the Bangladesh Centre of Advanced Studies (BCAS), gave the first talk on climate change to Bangladeshi academics and nongovernmental organizations (NGOs) in 1986. This early awareness, however, stayed very much within civil society in Bangladesh, and was not translated into policy for over a decade. One reason for the leadership of Bangladesh among the other LDCs is the history of environmental research and NGO action in Bangladesh, largely as a result of its extreme environmental vulnerability. The climate change agenda gave research and NGOs another focus, and the institutional framework was already there to be mobilized. Second, Bangladesh was fortunate to have academics and activists who were active in the international climate change arena and could disseminate information back to the country. This resulted in the location of leading environmental research institutions such as BCAS in Dhaka, which has been significant in coordinating both NGO and governmental climate change efforts.

Efforts were made from the earliest stages of climate change activity to sensitize all sectors of Bangladesh to the issues. What is surprising, therefore, is the lag between this awareness and policy-level action. As discussed, the international focus was, until recently, on emissions reductions. Bangladesh was an LDC already struggling to deal with poverty and existing climate variability; the suggestion of the abstract notion of climate change, being as it was heavily embedded in the global and scientific discourse, seemed largely irrelevant for Bangladesh when the international climate talks first began (Rahman, personal communication). The lack of initial political commitment had a knock-on effect for Southern representation at the international negotiations, because it was the academics, rather than the politicians, who could articulate the Southern climate change priorities. This only exacerbated the lack of Northern support for Southern climate change priorities. As a result, Bangladesh and other LDCs could not enjoy full participation in the international negotiations, further disincentivizing political interest in the issue of climate change as a whole.

This raises the question why, as shown in Box 1, there was so much mitigation research and activity, for example, the four mitigation studies carried out between 1993 and 2002 and the setting-up of a high-profile Designated National Authority (DNA) to coordinate CDM activities. Rahman (1997) suggests that it was because of the political belief that there were gains to be made not just from the additional funding for adaptation purposes (as later cemented in the 'Marrakech funds') but also significantly from the promise of investment in mitigation options, as later laid out at Kyoto. The first problem at this stage was therefore a confusion of incentives; while national priorities favored widespread adaptation action, the international focus until recently (particularly with regard to funding) had been on mitigation, meaning that government incentives lay primarily in mitigation. The second problem is the institutional structure of the government, which allows a disjoint between government action and national priorities. Bangladesh is governed centrally, allowing central government priorities to be favored and the inhibition of information from the rural areas where adaptation priorities are highest. In addition, national efforts with regard to climate change are largely uncoordinated. Adaptation is mainly dealt with by disaster reduction facilities within the Department of Environment under the MOEF (Ministry of Environment and Forestry), while mitigation activities are coordinated through a separate institutional framework, the two-tier DNA, with the Principal Secretary to the Prime Minister as head, and the second tier organized under the MOEF.

More recently, and in line with the global shift toward greater attention to adaptation, the adaptation agenda has made significant progress in climate policy in Bangladesh. In 2003 Bangladesh established a Comprehensive Disaster Management Programme (CDMP) with donor assistance, which has within its remit a goal of establishing an integrated approach to climate change and disaster management. Bangladesh was the first of the LDCs to complete the National Adaptation Plan of Action (NAPA), in 2005, and the Bangladesh government is integrating climate change into sectoral plans and national policies. For example, recommendations from the World Bank on the impacts of climate change have been incorporated into coastal zone management programs and adopted in the 
Box 1 National Efforts to Address Climate Change in Bangladesh

From “Addressing Climate Change in Bangladesh: National Efforts". DOE 2006 (Unpublished)

Bangladesh has undertaken a number of significant projects and achieved several milestones in the area of climate change

- Bangladesh signed the UNFCCC on 09.06.1992 and ratified it on 15.04.1994

- It accessed the Kyoto Protocol on 21.08.2001

- It participated in the US Climate Change Country Study Program and prepared its emission inventory and vulnerability assessment in 1994

- It also participated in the Asia Least Cost Green House Gas Abatement Strategy (ALGAS) Study in 1995-98. The ALGAS study included the formation of the national GHG abatement strategies consistent with national development priorities, and preparation of portfolio of GHG abatement projects

- It submitted its first National Communication to the UNFCCC in 2002. Bangladesh has taken up a project "Bangladesh: Climate Change Enabling Activity Self Assessment Exercise" as a first step to prepare its Second National Communication in the near future

- Bangladesh has completed a National Adaptation Plan of Action (NAPA) and has already submitted the NAPA to the UNFCCC in November 2005. The NAPA Document focuses on six sectors but in reality more sectors are covered

1. Forestry, Biodiversity and Land-Use

2. Agriculture, Fisheries and Livestock

3. Water, Coastal Areas, Natural Disaster and Health

4. Livelihood, Gender, Local Governance and Food Security

5. Industry and Infrastructure

6. Institutional and Policy Issues

- Bangladesh has accessed the Kyoto Protocol and under the Clean Development Mechanism it has established a two tier Designated National Authority (DNA). The tiers are National CDM Board and National CDM Committee. The DNA so far has approved four projects in waste and energy sectors of Bangladesh. These projects are at different stages of implementation. These projects are

1. Landfill Gas Extraction and Utilization at Matuail by Waste Concern

2. Composting Project at Gazipur and Kanchpur by Waste Concern

3. Installation of 30,000 Solar Home Systems (SHS) in rural households by Grameen Shakti and BCAS

4. Promotion of Energy Efficient Compact Florescent Lamp (CFL) in Rural Bangladesh (100,000 incandescent lamps to be replaced by CFL) by Grammen Shakti and BCAS

preparation of disaster preparedness plans and a water sector plan (Agrawala and others 2005). In 2007 the government announced an initiative to incorporate the impacts of climate change into development plans in its Poverty Reduction Strategy Paper (PRSP) revisions, proposing a draft policy and action plan by the end of 2008 (Huq and Ayers 2008).

The increase in action on adaptation in Bangladesh reflects not only the national priority that was always present, but also the global shift that has, to a large extent, facilitated this action. Having previously been the 'face' of environmental fragility, Bangladesh is fast becoming the example of good practice in climate change adaptation, used by many donors to showcase action and investment in adaptation. For example, the U.K. Department for International Development (DfID) Bangladesh has mainstreamed climate change activities into its development programs and, also, now provides direct support for programs that reduce vulnerability to climate variability and climate change. The DfID has screened its projects in Bangladesh based on profiles of climate and future hazard and vulnerability, and disaster risk reduction and climate change adaptation recommendations have been integrated into program activities (Lockwood and others 2006). The European Commission Country Strategy for Bangladesh for the period 2007-2013 also highlights climate change. The European Commission Strategy Paper explicitly recognizes that climate-change-related hazards are relevant to its donor strategy. (European Commission's Delegation to Bangladesh 2007).

Renewed attention to adaptation may partly explain why the initial flurry of activity with regard to mitigation and CDM has resulted in only four projects being approved by the DNA. As noted by one independent consultant on CDM in Bangladesh, "The government has lately refocused activities and attention back to where its expertise really lies; on adaptation. There are [sic.] no expertise for CDM, nor much real interest" (personal communication).

The two projects that have achieved DNA approval and are fully operational are both waste management projects implemented by the NGO Waste Concern, an organization that has been active in Bangladesh since 1995 and focuses on waste and energy projects. Both projects have been praised for their success in achieving investment and delivering on sustainable development benefits. For example, "Composting of Organic Waste in Dhaka" was the second CDM project to be registered in Bangladesh, and the first-ever composting project globally. It serves the dual benefits of producing compost and reducing methane emissions by diverting organic waste from dumping at a landfill (where anaerobic processes occur that generate higher levels of 
methane) to dumping at a composting plant (where aerobic processes occur). Such a project is highly suitable to the LDCs because, as in other LDC cities, the waste produced in Dhaka is mostly organic $(80 \%$ of solid waste consists of organic substances). This has a high potential for biofertilizer (compost) production. The waste is collected by trained 'waste pickers' and delivered to the composting site, where it is sorted and composted, thus preventing uncontrolled dumping of waste, creating jobs (particularly for less educated women), and creating valuable compost which combats highly problematic land degradation (Waste Concern 2005). The sustainable development and mitigation benefits of such a project are evident, and Waste Concern has been internationally acknowledged for their achievements in this regard through several awards.

Although praised for their success, however, Waste Concern acknowledges that they have faced an uphill struggle in implementing a CDM mitigation project in Bangladesh. Iftekhar Enayetullah, Co-Founder and Director of Waste Concern, states that because there was initially no history of CDM in Bangladesh, there was no attraction for investors and a wariness by the government without potential investment. Waste Concern overcame this by seeking out independent funding from The Netherlands, although Enayetullah admits that arousing interest in investing in CDM in such a small developing country with no history of mitigation was a challenge. Another problem was the number of permissions needed to implement the projects, 44 per project, meaning that operationalizing projects takes years (Enayetullah, personal communication). Enayetullah states that the government's lack of initial understanding of and interest in CDM was a major contributor to this lengthy and inefficient process. Waste Concern has therefore shown remarkable innovation and persistence in overcoming the barriers to achieving CDM certification in Bangladesh.

This review of adaptation and mitigation activities in Bangladesh has shown that the two have emerged and operated very independently of one another. When international attention and financial incentives were on mitigation, the domestic adaptation agenda suffered, and Bangladesh was alienated from the global climate change arena. The imposition of international climate change mitigation incentives on Bangladesh climate change policy resulted in a dysfunctional incorporation of mitigation activity into national policy frameworks. With renewed attention to adaptation, it seems that, although there is significant potential for Bangladesh to gain from CDM projects that enable mitigation and sustainable development, this potential is not being realized. The next section considers whether linking mitigation and adaptation in Bangladesh offers an opportunity to strengthen the capacity for both and maximize sustainable development gains.
Linking Mitigation and Adaptation in Bangladesh

Synergies between mitigation and adaptation can be explored by considering adaptation activities that have consequences for mitigation or mitigation activities that have consequences for adaptation (Klein and others 2007). Starting with adaptation, we can look to the Bangladesh National Adaptation Programme of Action (NAPA). The NAPA presents 15 Project Concept Notes, many of which show linkage possibilities. The most obvious is project 1 , "Reduction of Climate Change Through Coastal Afforestation with Community Participation" (MOEF 2005). While the rationale behind the project is that "the presence of forest plays a vital role in the stabilizing of shorelines and providing protection against cyclones and other extreme events," it is noted that one of the longer-term outcomes of the project will be a contribution to "the global carbon sequestration aspect" (MOEF 2005). While the offset contribution of adaptation projects will be less significant than that of projects that have the sole purpose of mitigation (because, for example, the choice of species will be in accordance with the ability to protect the shoreline rather than the sequestration potential), the potential to contribute to mitigation benefits is there.

Opportunities also exist to link mitigation and adaptation in Bangladesh's limited CDM portfolio, and Waste Concern is beginning to consider the possibilities for doing so within the composting project discussed under Climate Change Policy in Bangladesh (above). The sustainable development benefits of this project have already been discussed. However, there are also very clear adaptation benefits: as recognized by Waste Concern, the impacts of climate change will include agroecosystem stresses in drought-prone areas in Bangladesh. Enhancing soil organic matter content through organic manure to increase the moisture retention and fertility of soil both reduces vulnerability to drought and also has the additional benefit of increasing the carbon sequestration rates of the resulting crops (Ravindranath 2007). This creates a very neat mitigation-adaptation-sustainable development nexus: the composting projects mitigate GhGs directly through reduction of methane emissions and indirectly by contribution to carbon sequestration of crops; adaptation through soil improvement in drought-prone areas; sustainable development, because poverty is exacerbated when climate change reduces the flows of ecosystem services (Venema and Rehman 2007); and also through the other livelihoods benefits of the project noted under Climate Change Policy in Bangladesh (above).

Of course, such projects must be commercially viable, but Waste Concern suggests that financiers have shown an interest in linking mitigation with adaptation because CDM already necessitates a 'development dividend,' and the 
adaptation element of the project does not incur additional costs or reduce profit margins. Rather, it brings the concepts of climate change and development closer together; development as adaptation is no longer simply 'tacked on' to CDM, but a logical extension of a climate change project, also part of the climate change solution.

In addition, linking adaptation to mitigation may make mitigation options more attractive to policymakers in Bangladesh and generate incentives to strengthen the country's mitigative capacity, because it aligns mitigation more closely with the national climate change priorities. A better understanding of the benefits of mitigation for a country where the immediate priority is adaptation can improve Bangladesh's institutional receptivity for hosting CDM projects, strengthening the capacity of the DNA to be able to efficiently approve CDM projects that are consistent with the country's sustainable development priorities. This in turn may contribute to resolving the dichotomy between international incentives for climate change mitigation and national need, enabling Bangladesh to gain from international mitigation funding and fulfill adaptation and sustainable development objectives.

\section{Conclusions}

Current and future climate policy has the enormous task of aligning fundamental sustainable development objectives and adaptation priorities of the South with the need to achieve global engagement in mitigation. This paper has shown that the separate treatment of mitigation and adaptation in both climate science and policy has hindered progress in this task. Recent attention to exploring the synergies between mitigation and adaptation suggests that an integrated approach could go some way toward bridging the gap between Southern climate change priorities and global commons management. These issues have been explored through a case study analysis of climate change policy and practice in Bangladesh, an LDC where adaptation needs are high and mitigative capacity is low. This case study has illustrated that encouraging synergies between mitigation and adaptation at the project level can contribute to both climate change and development outcomes. Further, linking adaptation to mitigation may encourage faster progress in implementing CDM projects by making mitigation more relevant to policymakers in Bangladesh, increasing engagement in the global mitigation agenda in preparation for a post-Kyoto global strategy.

While Bangladesh is a very specific case, even among the LDCs, given its particular vulnerability coupled with its long history of environmentalism, this case study nevertheless strengthens the argument that, while combined mitigation and adaptation policy is not a magic bullet for a comprehensive climate policy, synergies, particularly at the project level, can contribute to the sustainable development goals of climate change and are worth exploring. In particular, this study supports the suggestion put forward by Swart and Raes (2007) that identifying CDM projects which decrease vulnerability to climate change, and reduce GhG emissions, can increase the host country's capacity to deal with climate risks and facilitate a more active role of developing countries in the UNFCCC and Kyoto Protocol process.

This has benefits beyond simply aligning mitigation and adaptation incentives in the South; it can also help to garner greater support for adaptation among advocates of the 'hard' mitigation agenda that have been cautious of adaptation in the past. Currently, the 'developments dividend' of CDM projects is largely removed from the original point of the project, which is to mitigate emissions effectively. Linkage projects provide a way to unite global emissions reductions with the impacts of emissions on the ground. They not only are reducing future emissions into the global system, but also are alleviating the local problems caused by emissions in the past. This helps to communicate a sense of responsibility for reducing carbon emissions in the first place, rather than the current 'offset' mentality which is encouraged by thinking of climate change in systemic mitigation terms alone. Acknowledging adaptation in mitigation highlights the inequitable distribution of climate change causes and impacts and raises awareness of environmental vulnerability in the South, and the poverty and politics behind it. Thus, it provides a new avenue for action against poverty in general, as well as the strengthening of environmental awareness and ethics.

Acknowledgments The authors would like to thank the reviewers of this piece, whose comments and recommendations contributed significantly to the improvement of the manuscript. Thanks also go to Dr. Tim Forsyth, London School of Economics, for his comments on early drafts of this work. We also acknowledge the Bangladesh Centre of Advanced Studies for their help in coordinating this research and all those who gave their valuable time in sharing their knowledge and opinions, both in the United Kingdom and in Bangladesh, particularly Dr. Ijaz Hossain (Bangladesh University of Engineering and Technology), Dr. Mizan R Khan (North South University), Dr. Moinul Islam Sharif (UNEP), Iftekhar Enayetullah and Maqsood Sinha (Waste Concern), Mohammad Reazuddin (Department of Environment), all those from the Climate Change Cell, Aminul Islam (UNDP), Ian Rector (CDMP), Mizanur Rahman (Practical Action), and Maeve Hall (WaterAid Bangladesh). This paper was updated by fieldwork supported by the Economic and Social Research Council.

\section{References}

Agrawala S, Ota T, Ahmed AU, Smith J, van Aalst M (2005) Development and climate change in Bangladesh: focus on coastal flooding and the Sundarbans. Organisation for Economic Co-operation and Development (OECD) 
Ahmed A, Alam M, Rahman A (1999) Adaptation to climate change in Bangladesh: future outlook. In: Huq S, Karim Z, Asaduzzuman M, Mahtab F (eds) Vulnerability and adaptation to climate change for Bangladesh. Kluwer Academic, New York

Alam M (2003) Bangladesh country case study for National Adaptation Programme of Action (NAPA) Workshop, Bhutan, BCAS, Dhaka, 9-11 September 2003

Brown K, Adger WN, Boyd E, Corbera-Elizalde E, Shackley S (2004) How do CDM projects contribute to sustainable development? Technical Report 16. Tyndall Centre for Climate Change Research, Manchester, UK

Burton I (2000) Adaptation to climate change and variability in the context of sustainable development. In: Gomez-Etcheverri L (ed) Climate change and development. Yale School of Forestry and Environmental Studies, New Haven, CT, pp 135-173

Cannon T (2000) Vulnerability analysis and disasters. In: Parker DJ (ed) Floods. Routledge, New York. Available at: http:// radixonline.org/resources/cannon-floods-chapter.doc

Dang HH, Michaelowa A, Tuan DD (2003) Synergy of adaptation and mitigation strategies in the context of sustainable development: the case of Vietnam. Climate Policy 3:S81-S96

DOE (2006) Addressing climate change in Bangladesh: national efforts. Department of Environment, Ministry of Environment and Forest, Government of the Peoples Republic of Bangladesh, Dhaka. Unpublished

Dowlatabadi $\mathrm{H}$ (2007) On integration of policies for climate and global change. Mitigation and Adaptation Strategies for Global Change 12:651-663

European Commission's Delegation to Bangladesh (2007) Bangladesh: European Community Country Strategy Paper for the period 2007-2013. European Commission

Forsyth T (2003) Critical political ecology: the politics of environmental science. Routledge Press, New York

Forsyth T (2007) Promoting the "development dividend" of climate technology transfer: Can cross-sector partnerships help? World Development 35:10

Golkany IM (2007) Integrated strategies to reduce vulnerability and advance adaptation, mitigation and sustainable development. Mitigation and Adaptation Strategies for Global Change 12:755786

Hajer MA (1995) The politics of environmental discourse: ecological modernization and the policy process. Clarendon Press, Oxford, UK

Halsnaes K, Verhagen J (2007) Development based climate change adaptation and mitigation-conceptual issues and lessons learned in studies in developing countries. Mitigation and Adaptation Strategies for Global Change 12:665-684

Huq S, Ayers JM (2007) Critical list: the 100 most vulnerable nations to climate change. Sustainable development opinion. IIED, London

Huq S, Ayers JM (2008) Climate change impacts and responses in Bangladesh. Briefing note prepared for the European Parliament. International Institute for Environment and Development, London; and Policy Department Economic and Scientific Policy, DG Internal Policies of the Union, Brussels

Huq S, Burton I (2003) Funding adaptation to climate change: What, who, and how to fund? Sustainable development opinion. IIED, London

Huq S, Grubb M (2007) Preface. Mitigation and Adaptation Strategies for Global Change 12:645-649

Huq S, Reid H (2007) Community based adaptation: an IIED briefing. International Institute of Environment and Development, London

IPPC (Intergovernmental Panel on Climate Change) (2001) In: Watson RT, The Core Writing Team (eds) Synthesis report 2001 - contribution of working group I, II and III to the third assessment report of the Intergovernmental Panel on Climate Change. Cambridge University Press, Cambridge, UK

IPCC (Intergovernmental Panel on Climate Change) (2007) Climate change 2007: impacts, adaptation and vulnerability. Working group II contribution to the Intergovernmental Panel on Climate Change Fourth Assessment Report: summary for policymakers. Cambridge University Press, Cambridge, UK

Jones RN, Dettmann P, Park G, Rogers M, White T (2007) The relationship between adaptation and mitigation in managing climate change risks: a regional response from North Central Victoria, Australia. Mitigation and Adaptation Strategies for Global Change 12:685-712

King DA (2004) Climate change science: Adapt, mitigate or ignore? Science 202:176-177

Kjellen B (2006) Forward. In: Adger WN, Paavola J, Huq S, Mace J (eds) Fairness in adaptation to climate change. MIT Press, Cambridge, MA

Klein, RJT, Huq S, Denton F, Downing TE, Richels RG, Robinson JB, Toth FL (2007) In: Parry ML, Canziani OF, Palutikof JP, van der Linden PJ, Hanson CE (eds) Inter-relationships between adaptation and mitigation. Climate change 2007: impacts, adaptation and vulnerability. Contribution of working group II to the fourth assessment report of the Intergovernmental Panel on Climate Change. Cambridge University Press, Cambridge, UK, pp 745-777

Litfin K (1994) Ozone discourses: science and politics in global environmental cooperation. Columbia University Press, New York

Lockwood H, Schoen P, Taher M (2006) DFID-Bangladesh: output to purpose review of Comprehensive Disaster Management Programme. A. Consultants, UNDP

MOEF (Ministry of Environment and Forest, Government of the People's Republic of Bangladesh) (2005) National Adaptation Programme of Action. Final report. MOEF, Dhaka

Müller B (2002) Equity in climate change: the great divide. Oxford Institute for Energy Studies, Oxford

Munasinghe M, Swart R (2004) Primer on climate change and sustainable development: facts, policy analysis and applications. Cambridge University Press, Cambridge, UK

Oxfam International (2007) What's needed in poor countries, and who should pay? Oxfam Briefing Paper. Oxfam International, Oxford, UK

Pielke R, Prins G, Rayner S, Sarewitz D (2007) Lifting the taboo on adaptation. Nature 445:597-598

Rahman A (1997) The South is acting. Our planet 9.3. Bangladesh Centre for Advanced Studies, Dhaka

Ravindranath NH (2007) Mitigation and adaptation synergy in forest sector. Mitigation and Adaptation Strategies for Global Change 12:843-853

Rozenweig C, Tubiello FN (2007) Adaptation and mitigation strategies in agriculture: an analysis of potential synergies. Mitigation and Adaptation Strategies for Global Change 12:855873

Swart R, Raes F (2007) Making integration of adaptation and mitigation work: mainstreaming into sustainable development policies? Climate Policy 7:288-303

Taiyab N (2006) Exploring the market for voluntary carbon offsets. IIED, London

UNFCCC (United Nations Framework Convention on Climate Change) (1992) United Nations Framework Convention on Climate Change: convention text. UNFCCC, Bonn

UNFCCC (United Nations Framework Convention on Climate Change) (2002) The Delhi ministerial declaration on climate change and sustainable development. UNFCCC, Bonn

Venema HD, Cisse M (2004) Seeing the light: adapting to climate change with decentralized renewable energy in developing 
countries. International Institute for Sustainable Development, Winnipeg, Canada

Venema HD, Rehman IH (2007) Decentralized renewable energy and the climate change mitigation-adaptation nexus. Mitigation and Adaptation Strategies for Global Change 12:875-900

Waste Concern (2005) Composting of organic waste in Dhaka: Project Design Document Form (CDM PDD). Version 2. Available at: http://cdm.int. Accessed March 9, 2007

Willbanks TJ, Sathaye J (2007) Integrating mitigation and adaptation as a response to climate change: a synthesis. Mitigation and Adaptation Strategies for Global Change 12:957-962

Wilbanks TJ, Kane SM, Leiby PN, Perlack RD, Settle C, Shogren JF, Smith JB (2003) Integrating mitigation and adaptation as possible responses to global climate change. Environment 45:28-38

Willbanks TJ, Sathaye J, Klein RJT (2007a) Introduction. Mitigation and Adaptation Strategies for Global Change 12(5)

Willbanks TJ, Leiby P, Perlack R, Ensminger JT, Wright SB (2007b) Toward an integrated analysis of mitigation and adaptation: some preliminary findings. Mitigation and Adaptation Strategies for Global Change 12:713-725

World Bank (2006) An investment framework for clean energy and development: a progress report. DC2006-0012. World Bank, Washington, DC 